\title{
Numerical Investigation of the Best Efficient Tandem Solar Cell Structures Using the Base Cell Models of MZO/CdTe and CdS/CIGS Cell Structures
}

\author{
Ratnasinghe D.R. ${ }^{1 *}$, Attygalle M.L.C. ${ }^{1}$ \\ ${ }^{1}$ Department of Physics, Faculty of Applied Sciences, University of Sri Jayewardenepura, Sri Lanka
}

\begin{abstract}
Tandem solar cells have been researched to enhance the performance of the second generation (II-VI) thin-film solar cells. In this study, we have developed an efficient tandem solar cell model by optimizing the thickness of the (II-VI) layers and by introducing $\mathrm{Mg}$ doped $\mathrm{ZnO}$ as the window material for the top cell. The tandem solar cell model consists of a top cell, n-MZO/p-CdTe and a bottom cell, n-CdS/p-Cu(In, $\mathrm{Ga}_{\mathrm{Se}} \mathrm{e}_{2}$ (CIGS). The parameters of the computational model, such as thicknesses of $n$-CdS, $p$-CIGS. $p$ CdTe has been varied to improve the efficiency of the tandem solar cell and compared with the previous researched single junction thin-film solar cells. All the numerical experiments were conducted under one sun illumination condition with AM 1.5 G solar spectrum by using the Analysis of Microelectronic and Photonic Structures simulation software (AMPS-1D) and Solar Cell Capacitance Simulator (SCAPS 1-D) software. The observed open circuit voltage was $1.413 \mathrm{~V}$ and the efficiency wa sincreased to $28.84 \%$ and this is a huge improvement compared to the reported recorded best research cell values of $0.8 \mathrm{~V}$ and $24.2 \%$ respectively for single junction solar cell.
\end{abstract}

KEYWORDS : AMPS-1D, SCAPS-1D, Tandem solar cell, II-VI photovoltaics, AM1.5G, Thin-film PV 


\section{INTRODUCTION}

The efficiency of a thin-film solar cell can be increased by using two or more cells connected in series such as one cell can absorb the part of the spectrum and the other cells can absorb the rest of the spectrum. Each cell can individually optimize to incresase the overall efficiency and these are called tandem/ Multi-junction solar cells. Tandem solar cells/Multi-junction solar cells are promising to solve the energy demand in the PV industry.

Thin film PV solar cells have been used to create Tandem/multi-junction solar cells(Guha et al. 2013). This is because of the very attractive theoretical efficiency of $87 \%$ under highly concentrated sunlight for an infinite number of junctions and the cells can be made with cost-effective manufacturing techniques(De Vos 1980). However, the understandings of the behavior of these devices in the real world are very poor due to their complicated structures. Only analytical modeling with the help of numerical simulations can explain the behavior of the cells under certain assumptions and simplifications. Therefore Numerical modeling/simulation is required to understand the electronic and optical properties of these devices.

In this research, we tried to make the best efficient tandem solar cell structures by selecting MZO/CdTe and CdS/CIGS cell structures. CdS is replaced by n:MZO (magnesium-doped zinc oxide)in the $\mathrm{CdS} / \mathrm{CdTe}$ cell and this is used as the top cell(Sites 2015). The replacement of MZO layer will help to increase the current density. The TCO using with MZO makes high flexibility and high transparency. The CdS/CIGS cell used as the bottom cell of the tandem structure (Fig. 1)

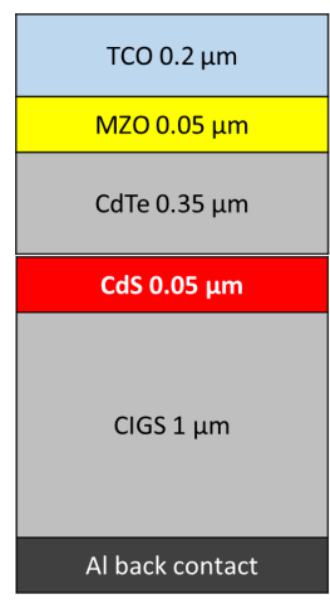

Figure 1. Structural view of baseline MZO/CdTe (Top) and CdS/CIGS (Bottom) solar cell (Ehemba et al. 2017).

\section{RESEARCH METHODOLOGY / MATERIALS AND METHODS}

One-dimensional Analysis of Microelectronic and Photonic Structure (AMPS-1D) simulation software (Enam et al. 2017) can be used to model any photonic device with semiconductor junctions. One dimensional Solar Cell Capacitance Simulator software (SCAPS$1 \mathrm{D}$ ) can be also used as a simulation program for numerical modeling of single and multi-junction photovoltai structures. This is developed at the Department of Electronics and Information Systems (ELIS) of the University of Gent, Belgium (Burgelman et al. 2000). This software was originally developed for cell structures of the CuInSe $\mathrm{C}_{2}$ and the CdTe family and it is also applicable to crystalline solar cells ( $\mathrm{Si}$ and $\mathrm{GaAs}$ family) and amorphous cells (a-Si and micromorphous Si) (Heriche et al. 2017).

\subsection{Modeling}

There are 3 different types of cell configurations of tandem cell structures (Olson et al. 2011). In this model we have consider the two terminal subcell 
Numerical investigation of the best efficient tandem solar cell structures using the base cell models of MZO/CdTe and CdS/CIGS cell structures

configuration. The subcells are not isolated from each other. There is a tunnel junction in between the top subcell and the bottom subcell. This configuration requires that the subcells be of the same polarity and the photocurrents of the subcells need to be closely matched(Olson et al. 2011).

In two terminal configuration, the top subcell should have a high energy band gap and the bottom subcell should have a low energy band gap. The high energy phtons are absorbed by the top cell and the rest of the photon energy penetrates through the cell. These low energy photons are absorbed by the bottom cell.

\subsection{Material Selection}

CdS and MZO(Enam et al. 2017) thin films have properties that are applicable to solar cell fabrication. They have good optical transmittance, a wide band gap, and good electrical properties. CdS also have a high absorption coefficient (Polyanskiy 2018), electron affinity, and this is an easy ohmic contact which is an electrical junction between two semiconductors obeys the Ohm's law. CdTe photovoltaic is the only thin-film technology with lower costs than conventional solar cells made of crystalline silicon. This material has the smallest carbon footprint, of all solar technologies(Alajlani et al. 2018). Also CdTe has higher absorption coefficients for AM1.5G spectrum in lower wavelengths. Here $\mathrm{Cu}(\mathrm{In}, \mathrm{Ga}) \mathrm{Se}_{2}$ (CIGS) uses as an absorber layer and it has greater absorption coefficients for AM1.5G spectrum in high wavelengths.

\subsection{Simulation}

The performance of the proposed solar cell structure has been examined by using SCAPS-1D or AMPS-1D software. The SCAPS software cannot be used directly to simulate multi-junction solar cell models. A tandem connection was made by using a SCAPS script.

The simulation parameters were suggested during the modeling and these values depend on theoretical analysis and literature reviews. The multi-junction concept is used in this modified solar cell (Kim et al. 2017) as single junction solar cells can't absorb low energy photons. Initially, p-CdTe, n-CdS, p-CIGS layer thicknesses have been varied.

TABLE. 1 Material parameters of the tandem solar cell (Burgelman et al. 2000).

\begin{tabular}{|l|c|c|c|c|c|}
\hline \multicolumn{1}{|c|}{ Parameters } & $\mathrm{n}-\mathrm{TCO}$ & $\mathrm{n}-\mathrm{MZO}$ & $\mathrm{p}$-CdTe & $\mathrm{n}$-CdS & $\mathrm{p}$-CIGS \\
\hline Thickness, $(\mu \mathrm{m})$ & 0.2 & 0.01 & Variable & Variable & Variable \\
\hline Dielectric ratio, $\left(\varepsilon / \varepsilon_{0}\right)$ & 9 & 10 & 9.4 & 10 & 13.6 \\
\hline Electron mobility, $\mu \mathrm{N}\left(\mathrm{cm}^{2} / \mathrm{Vs}\right)$ & 50 & 5.93 & 320 & 100 & 100 \\
\hline Hole mobility, $\mu \mathrm{P}\left(\mathrm{cm}^{2} / \mathrm{Vs}\right)$ & 25 & 25 & 40 & 25 & 25 \\
\hline Acceptor concentration, $\left(\mathrm{cm}^{-3}\right)$ & - & - & $2.0 \times 10^{14}$ & - & $2.0 \times 10^{16}$ \\
\hline Donor concentration, $\left(\mathrm{cm}^{-3}\right)$ & $5.0 \times 10^{20}$ & $1.0 \times 10^{17}$ & - & $1.1 \times 10^{18}$ & - \\
\hline Band gap, $\mathrm{E}_{\mathrm{g}}(\mathrm{eV})$ & 3.7 & 3.41 & 1.5 & 2.4 & 1.15 \\
\hline Density of states, $\mathrm{NC}\left(\mathrm{cm}^{-3}\right)$ & $2.2 \times 10^{20}$ & $2.2 \times 10^{18}$ & $8.0 \times 10^{17}$ & $2.2 \times 10^{18}$ & $2.2 \times 10^{18}$ \\
\hline Density of states, $\mathrm{NV}\left(\mathrm{cm}^{-3}\right)$ & $1.8 \times 10^{19}$ & $1.8 \times 10^{19}$ & $1.8 \times 10^{19}$ & $1.8 \times 10^{19}$ & $1.8 \times 10^{19}$ \\
\hline Electron affinity, $\chi(\mathrm{eV})$ & 4.5 & 4.5 & 3.9 & 4 & 4.5 \\
\hline
\end{tabular}




\section{RESULTS \& DISCUSSION}

The thickness of n-CdS, p-CIGS, and pCdTe layer have been varied to find the optimum values of CdTe/CIGS tandem solar cells. Finally, the highest efficiency and the largest open circuit voltage $\left(\mathrm{V}_{\mathrm{oc}}\right)$ are observed. The observed optimal layer thickness values for the CdTe, CdS and CIGS layers were $0.35 \mu \mathrm{m}, 0.5 \mu \mathrm{m}$, and 1 $\mu \mathrm{m}$ respectively.

The recorded optimal value for the efficiency of CdS/CdTe baseline cells is about 19.701\%(Enam et al. 2017). The observed $\mathrm{V}_{\mathrm{oc}}, \mathrm{J}_{\mathrm{sc}}$ and the Efficiency values of the modified tandem cell model are $1.413 \mathrm{~V}, 24.501 \mathrm{~mA} / \mathrm{cm}^{2}$ and 28.8493\% respectively(Figure 2 ).

Here we have observed that the thickness of the CdTe layer highly affects efficiency of the tandem solar cell. In the optimum condition, the structure showed it's maximum performance. (Figure 3.)

According to the working principle of series tandem connection it showed the maximum current density at the optimized thicknesses. At that time the shot circuit currents of the both cells were matched each other confirming the series connection between the top and the bottom cell. The voltage difference between the terminals of the tandem cell was closely equal to the summation of top and bottom cells.

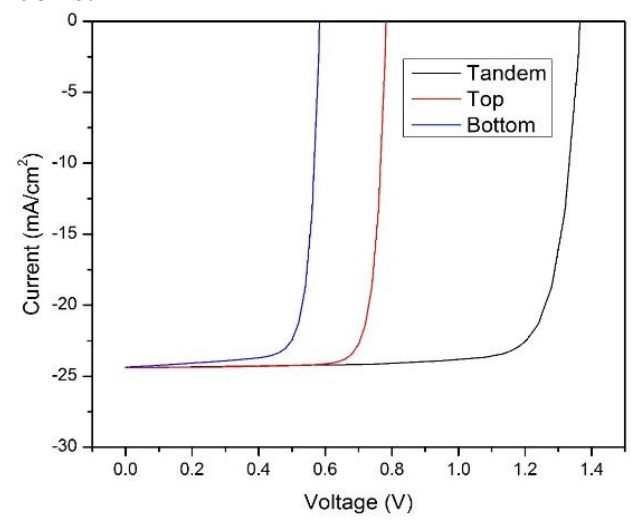

Figure 2. I-V characteristic curves

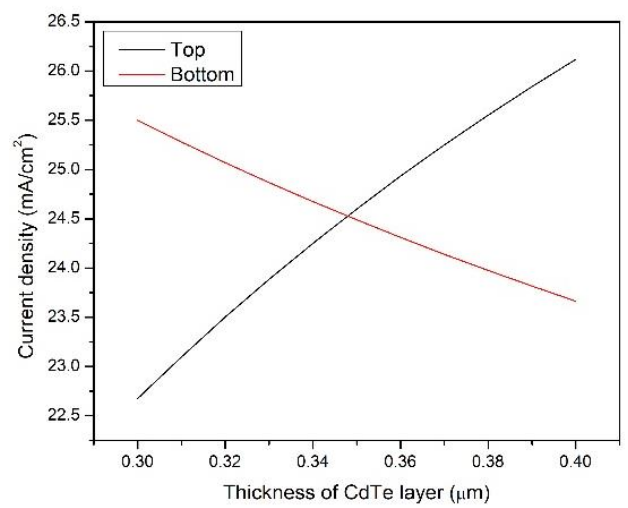

Figure 3. Short circuit current density variation of top and bottom cell with the thickness of the CdTe layer

\section{CONCLUSION/FURTHER WORK}

The maximum efficiency can be obtained at the optimized current matching condition. In a perfect tandem connection, short circuit currents should be matched and voltages should be added. The $\mathrm{V}_{\text {oc }}$ value and efficiency were increased as expected. The thickness of the CdTe absorber layer has high effect on the efficiency of the tandem cell.

Some researches found out that the temperature has an effect on the performance of the solar cell(Ferouani et al. 2011). The further investigations will be conducted to optimize the same model for the operating temperature and the carrier concentration of the subcell layers.

\section{REFERENCES}

Alajlani, Y., Alaswad, A., Placido, F., Gibson, D. and Diyaf, A. (2018) 'Inorganic thin film materials for solar cell applications' in Reference Module in Materials Science and Materials Engineering, Elsevier BV.

Burgelman, M., Niemegeers, A., Decock, K., Degrave, S. and 
Numerical investigation of the best efficient tandem solar cell structures using the base cell models of MZO/CdTe and CdS/CIGS cell structures

Verschraegen, J. (2000) Solar Cell

Capacitance Simulator, email to [accessed

De Vos, A. (1980) 'Detailed balance limit of the efficiency of tandem solar cells', Journal of Physics D: Applied Physics, 13(5), 839.

Ehemba, A. K., Socé, M. M., Domingo, J. J., Cisse, S. and Dieng, M. (2017) 'Optimization of the Properties of the Back Surface Field of a $\mathrm{Cu}(\mathrm{In}, \mathrm{Ga}) \mathrm{Se} 2$ Thin Film Solar Cell', American Journal of Energy Research, 05(02), 57-62.

Enam, F. M. T., Rahman, K. S., Kamaruzzaman, M. I., Sobayel, K., Bais, B., Akhtaruzzaman, M., Alamoud, A. R. M. and Amin, N. (2017) 'Design Prospects of Cadmium Telluride/Silicon (CdTe/Si) Tandem Solar Cells from Numerical Simulation', Optik International Journal for Light and Electron Optics.

Ferouani, A., Boudia, M. M., Cheknane, A. and Benyoucef, B. (2011)

'Temperature Effect of Electrical Properties of Cigs Solar Cell', Journal of Fundamental and Applied Sciences, 3(1), 77-84.

Guha, S., Yang, J. and Yan, B. (2013) 'High efficiency multi-junction thin film silicon cells incorporating nanocrystalline silicon', Solar Energy Materials and Solar Cells, 119, 1-11.

Heriche, H., Rouabah, Z. and Bouarissa, N. (2017) 'New ultra thin CIGS structure solar cells using SCAPS simulation program', International Journal of Hydrogen Energy, 42(15), 9524-9532.
Kim, K., Gwak, J., Ahn, S. K., Eo, Y.-J., Park, J. H., Cho, J.-S., Kang, M. G., Song, H.-E. and Yun, J. H. (2017) 'Simulations of chalcopyrite/c-Si tandem cells using SCAPS-1D', Solar Energy, 145, 52-58.

Olson, J. M., Friedman, D. J. and Kurtz, S. (2011) 'High-Efficiency III-V Multijunction Solar Cells' in Luque, A. and Hegedus, S., eds., Handbook of Photovoltaic Science and Engineering, John Wiley \& Sons, Ltd, 259411.

Polyanskiy, M. N. (2018) 'Refractive index database', [online], available: https://refractiveindex.info/ [Accessed 2019-06-25 2019].

Sites, J. R. (2015) High-Efficiency, Commercial Ready CdTe Solar Cells, Colorado State Univ., Fort Collins, CO (United States). 